This item was submitted to Loughborough's Research Repository by the author.

Items in Figshare are protected by copyright, with all rights reserved, unless otherwise indicated.

\title{
Two-dimensional simulation of cold start processes for proton exchange membrane fuel cell with different hydrogen flow arrangements
}

\section{PLEASE CITE THE PUBLISHED VERSION}

https://doi.org/10.1016/j.ijhydene.2020.04.187

\section{PUBLISHER}

Elsevier BV

\section{VERSION}

AM (Accepted Manuscript)

\section{PUBLISHER STATEMENT}

This paper was accepted for publication in the journal International Journal of Hydrogen Energy and the definitive published version is available at https://doi.org/10.1016/j.ijhydene.2020.04.187

\section{LICENCE}

CC BY-NC-ND 4.0

\section{REPOSITORY RECORD}

Wu, Kangcheng, Xu Xie, Bowen Wang, Zirong Yang, Qing Du, Jin Xuan, Bingfeng Zu, Zhi Liu, and Kui Jiao. 2020. "Two-dimensional Simulation of Cold Start Processes for Proton Exchange Membrane Fuel Cell with Different Hydrogen Flow Arrangements". Loughborough University. https://hdl.handle.net/2134/12932806.v1. 


\section{Two-dimensional simulation of cold start}

\section{processes for proton exchange membrane fuel cell with different hydrogen flow arrangements}

\section{Abstract}

Proton exchange membrane (PEM) fuel cells with an off-gas recirculation anode (ORA) or dead-ended anode (DEA) are widely adopted in engineering. However, those two hydrogen flow arrangements may cause anodic water and nitrogen accumulation in comparison with the flow-through anode (FTA) mode, which causes significant performance degradation. In this paper, a two-dimensional cold-start model is developed with detailed consideration of water phase changes and the nitrogen crossover phenomenon. A simplified electrochemical module is built to calculate the current density distribution in the model. The simulation results are consistent with the experimental data at both subzero temperatures and normal operating temperatures. The effects of hydrogen flow arrangements, flow 
24 configurations, and startup strategies are investigated during startup process from 25 subzero to normal operating temperatures. Much less ice is generated in counter-flow 26 cases than in co-flow cases during constant current operation. A relatively lower 27 startup voltage can effectively shorten the cold-start process and enhance the 28 cold-start capacity for the PEM fuel cell. The ORA mode has the best hydrogen flow 29 arrangement due to its general abilities, including higher hydrogen utilization 30 efficiency, higher anodic nitrogen tolerance, better output performance and better 31 startup capability.

32 Keywords: PEM fuel cell; Hydrogen flow arrangements; Cold-start process; Start 33 strategies; Flow configurations 
Nomenclature

$a$

A

ASR

$c$

$C_{p}$

$D$

EW

F

$h$

$i$

$\kappa$

K

M

$n$ water activity

area $\left(\mathrm{m}^{2}\right)$

internal resistance of the cell $\left(\Omega \mathrm{m}^{2}\right)$

mole concentration $\left(\mathrm{mol} \mathrm{m}^{-3}\right)$

specific heat $\left(\mathrm{J} \mathrm{kg}^{-1} \mathrm{~K}^{-1}\right)$

diffusion coefficient $\left(\mathrm{m}^{2} \mathrm{~s}^{-1}\right)$

equivalent weight of the membrane

$\left(\mathrm{kg} \mathrm{kmol}^{-1}\right)$

Faraday's constant $\left(\mathrm{C} \mathrm{mol}^{-1}\right)$

latent heat $\left(\mathrm{J} \mathrm{kg}^{-1}\right)$;

convective heat transfer coefficient $\left(\mathrm{W} \mathrm{m}^{-2} \mathrm{~K}^{-1}\right)$

local current density $\left(\mathrm{A} \mathrm{m}^{-2}\right)$

electrochemical reaction rate $\left(\mathrm{A} \mathrm{m}^{-3}\right)$

electrical conductivity $\left(\mathrm{S} \mathrm{m}^{-1}\right)$

permeability $\left(\mathrm{m}^{2}\right)$

molecular weight $\left(\mathrm{kg} \mathrm{mol}^{-1}\right)$

moles of electrons production per mole of 
reactant consumption

$n_{d}$

$p$

$p_{c}$

$R$

$S$

$S$

ST

$t$

$T$

V

$x, y$

Greek symbols

$\alpha$

$\delta$

$\varepsilon$

$\eta$ electro-osmotic coefficient

pressure $(\mathrm{Pa})$

capillary pressure $(\mathrm{Pa})$

ideal gas constant $\left(\mathrm{J} \mathrm{K}^{-1} \mathrm{~mol}^{-1}\right)$

Saturation

source term $\left(\mathrm{mol} \mathrm{m} \mathrm{m}^{-3} \mathrm{~s}^{-1}\right)$

stoichiometric ratio

time (s)

temperature (K)

voltage (V);

volume $\left(\mathrm{m}^{-3}\right)$

coordinate position (m) transfer coefficient

thickness (m)

Porosity

voltage loss (V) 
$\kappa$

$\theta$

$\lambda$

$\mu$

$\rho$

$\sigma$

$\omega$

\section{Superscript and}

subscripts

0

act

ave

c

control

cond

eff

en

eq

f phase change rate $\left(\mathrm{s}^{-1}\right)$

contact angle $\left({ }^{\circ}\right)$

water content

dynamic viscosity $\left(\mathrm{kg} \mathrm{m}^{-1} \mathrm{~s}^{-1}\right)$

density $\left(\mathrm{kg} \mathrm{m}^{-3}\right)$

electrical conductivity $\left(\mathrm{S} \mathrm{m}^{-1}\right)$

volume fraction of ionomer standard condition

activation loss

Average

Cathode

control volume

Condensation

Effective

Environment

Equilibrium

frozen membrane water 
fusn

g

$\mathrm{H}_{2}$

$\mathrm{H}_{2} \mathrm{O}$

ice

in

lq

$\mathrm{nf}$

nernst

ohm

out

$\mathrm{O}_{2}$

BP

ref

sat

vp

lq-ice

nf-lq
Fusion

Gas

Hydrogen

Water

Ice

Inlet

super-cooled (liquid) water

nonfrozen membrane water

Nernst

Ohmic

output; outlet

Oxygen

bipolar plate

reference condition

saturation state

water vapor

between liquid water and ice

between nonfrozen membrane water and

liquid water 
nf-vp

vp-lq

vp-ice between nonfrozen membrane water and

vapor

between vapor and liquid water

between vapor and ice 


\section{Introduction}

37 Proton exchange membrane (PEM) fuel cell is a potential alternative to the next generation of automobile powertrain due to its high efficiency, high power density, and zero/low emissions $[1,2]$. However, the ability of successful and rapid startup from subfreezing temperatures remains great technical obstacles before large-scale commercialization $[3,4]$. Therefore, a comprehensive understanding of the startup process from subzero to normal operating temperatures is of vital importance to enhance the performance and durability of the PEM fuel cell [5].

To investigate the efforts of operating conditions and design parameters during the cold-start process, many experimental and numerical studies have been conducted. Tajiri et al. [6] compared the effect of the initial temperatures, current density, dry purge and membrane thickness on the cold-start capability by experiments. Jiao et al. [7] investigated the behavior of the cold-start process under different start voltages, initial water contents and initial cell temperatures by simulations. Xie et al. [8] conducted several experiments to investigate the effects of three different

51 ionomer/carbon ratios on the cold-start process and analyzed the consequences with

52 theoretical water transport. Yang et al. [9] studied the influence of various contact 53 angles and porosities of micro-porous layer on the performance of PEM fuel cell 54 during the cold-start process and gave suggestions to the design of the membrane 55 electrode assembly.

56 To better comprehend the behavior of the PEM fuel cell at subzero temperatures,

57 Morin et al. [10] tested the water management in the PEM fuel cell by small-angle 58 neutron scattering (SANS) and electrochemical impedance spectroscopy (EIS) 59 techniques. The experiments showed that a large current load could lead to 60 dehydration in a thick membrane. Lin et al. [11] used the printed circuit board 61 technology to measure the current density distributions and optimize start strategy for 
62 the cold start. Initial voltage load and setup temperature are also investigated in detail 63 [12]. Later, they segmented the PEM fuel cell to study the distribution of internal current density [13] and obtained better understanding of cell behaviors with different flow fields [14]. Jiao et al. [15] launched a 3D model to capture the dynamic features of the cold-start processes in the PEM fuel cell. Then, they investigated the impacts of the initial temperature, load condition and flow arrangement on dynamic performances through in-situ experiments [16]. Gwak et al. [17] performed cold-start simulations for PEM fuel cells from subfreezing to normal operating temperatures and predicted various stages of the processes. They concluded that the co-flow configuration could result in more ice growth and accumulation during subzero temperature operation than the counter-flow case. Zhan et al. [18] tested several reheating methods for a PEM fuel cell stack starting from subfreezing temperatures. The experimental results showed that when the operating temperature exceeded a reference value, e.g., $297 \mathrm{~K}$ in this study, the performance of the stack could be improved by humidifying the reactants and circulating the coolant. In those studies, the flow-through anode (FTA) mode is usually adopted due to its operational convenience [19]. However, the FTA mode can suffer from low hydrogen utilization efficiency, which limits the use of this hydrogen supply arrangement in engineering.

The dead-ended anode (DEA) mode and off-gas recirculation anode (ORA) mode are widely used in practical applications to enhance the hydrogen utilization efficiency [20]. Compared with the ORA mode, the DEA mode significantly reduces the complexity of hydrogen supply [21]. Many studies have been conducted to investigate the effects of hydrogen supply modes, focusing on the hydrogen efficiency, anodic nitrogen accumulation, and corresponding purge strategies. Chen et al. [21] focused on the optimal purge strategy of the DEA operation and developed a dynamic model to predict the liquid water accumulation in the anode and amount of hydrogen wasted during the purge. The results showed a balance between the maximum thermodynamic efficiency and minimum hydrogen loss during the DEA operation. 
Yesilyurt et al. [22] presented a dynamic 1D model of the PEM fuel cell in the DEA mode. The computation results showed that the decline of output performance was related to nitrogen crossover and accumulation. Yang et al. [23] built a transient model of the PEM fuel cell with DEA to study the nitrogen crossover and accumulation in varying-load operations. The operating current was considered to affect the nitrogen crossover and purge frequency. The simulation results showed that the model predictions corresponded to the experimental data. Yang et al. [24] examined the current density distributions in the PEM fuel cell in the DEA mode with different boundary conditions. The experimental data indicated that nitrogen first accumulated near the outlet of the anode channel and subsequently diffused to the upstream area, which decreased the local current density at the exit of the anode channel.

The PEM fuel cell with ORA has been widely used in vehicles, such as the Toyota Mirai in 2016 and Honda FCX Clarity in 2017 [20]. Bao et al. [25] presented a dynamic 1D model to study the effect of the injection pump on the PEM fuel cell with ORA. The simulation results showed that the 1D fuel cell model had good accuracy and could predict the water flooding in the cathode. Wang et al. [26] simulated the dynamic processes with two different purge strategies in the PEM fuel cell with ORA. He found that a $3 \%$ bleed rate was the best choice in consideration of the hydrogen use efficiency and nitrogen accumulation. Ahluwalia and Wang [27] developed a dynamic model to study the nitrogen accumulation during the ORA operation and effects on the performance of the PEM fuel cells with different bleed rates. The investigations indicated that a small bleed rate could make the nitrogen fraction to accumulate over 50\% during the operations. Promislow et al. [28] presented an analytical model in the ORA mode to study the best strategy of bleed rate for PEM fuel cells. Wang et al. [29] introduced a quasi-2D dynamic model in the ORA mode and studied the regularities of nitrogen distributions in the anode. The results showed 
117 that the PEM fuel cell with ORA performed better in various aspects at normal

118 operating temperatures than those with DEA.

119 However, the studies about the startup processes from subzero to normal temperatures

120 with DEA or ORA are hard to find in the literature. To find the advantages and

121 weaknesses of the three hydrogen flow modes in the start-up processes, numerical or

122 analytical model must be developed to capture the dynamic characteristics in a large

123 range of temperatures. Therefore, we develop a quasi-2D transient multiphase PEM

124 fuel cell model with a simplified electrochemical model in this paper. The differences

125 among the three anode flow arrangements (FTA, DEA, ORA) from subzero to normal

126 operating temperatures are analyzed. The effects of flow configurations (co-flow \&

127 counter-flow) and startup strategies (constant current \& constant voltage) are also

128 investigated.

\section{Mathematical Model}

130 In general, five types of water, including super-cooled water must be considered

131 during startup operation. Hydrogen flow arrangements may affect the water content

132 and local current density distributions. The heat transport can be more complex for

133 subzero environmental temperatures. The gas transport, heat transport and

134 electrochemical reaction must be synthetically considered.

$135 \quad 2.1$ Model description

136 Fig. 1 displays a schematic diagram of the quasi-two-dimensional model for the 137 proton exchange membrane (PEM) fuel cell with counter-flow configuration. The 138 entire cell is divided into eleven layers according to structural features, including 139 bioplate (BP), channel (CH), gas diffusion layer (GDL), micro-porous layer (MPL), 140 catalyst layer (CL) and membrane (MEM). Each layer is divided into $N$ segments 141 along the flow direction (Y-axis). The structural parameters and operating conditions 142 are listed in Table 1. 
143 In this model, super-cooled water is considered in the water phase change mechanism

144 during the subzero process [30]. The generated water from electrochemical reactions

145 is considered to be membrane water and initially absorbed in CCL [4].

\subsection{Assumptions}

147 To simplify the calculation, several assumptions are adopted in the model:

148 (1) The flow in channels is laminar due to the low Reynolds number.

149 (2) All gas species are treated as ideal gas [5].

150 (3) The gas pressure remains constant along the flow direction in the channels

151 because the pressure drop can be ignored compared to operation atmosphere [29].

152 (4) The electric potential is identical all over the surface of the bipolar plate because

153 of the high electric conductivity of the metal material.

154 (5) Considering the real geometry, the diffusion transport along the flow direction

155 and convection transport in the gas diffusion layer (GDL), micro-porous layer (MPL)

156 and catalyst layer (CL) can be ignored in comparison with the diffusion and

157 convection transport in other directions [29].

\subsection{Electrochemical module}

159 The output voltage $\left(V_{\text {out }}, \mathrm{V}\right)$ is expressed as follows based on Nernst voltage $\left(V_{\text {nernst }}\right.$,

$160 \mathrm{~V})$, the activation overpotential ( $\eta_{\text {act,a }}$ and $\left.\eta_{\text {act,c }}, \mathrm{V}\right)$, concentration overpotential

$161\left(\eta_{\text {conc,a }}\right.$ and $\left.\eta_{\text {conc, }}, \mathrm{V}\right)$ and ohmic overpotential $\left(\eta_{\text {ohmic }}, \mathrm{V}\right)$.

162

$$
V_{\text {out }}=V_{\text {nernst }}+\eta_{\text {act,a }}+\eta_{\text {act, } \mathrm{c}}+\eta_{\text {conc,a }}+\eta_{\text {conc, }}+\eta_{\text {ohmic }}
$$

163 Considering the reactant and product, Nernst voltage is calculated as 


$$
V_{\text {nernst }}=1.229-0.846 \times 10^{-3} \times(T-298.0)+\frac{R T}{2 F} \ln \left(p_{\mathrm{H}_{2}} p_{\mathrm{O}_{2}}^{0.5}\right)
$$

165 where $p_{\mathrm{H}_{2}}$ and $p_{\mathrm{O}_{2}}\left(\mathrm{P}_{\mathrm{a}}\right)$ are the partial pressures for hydrogen and oxygen, 166 respectively.

167 In this electrochemical module, Tafel equation is applied to calculate the anodic and 168 cathodic activation loss [5]:

$$
\begin{aligned}
& \eta_{\mathrm{act}, \mathrm{a}}=-\frac{R T}{2 \alpha_{\mathrm{a}} F} \ln \left(\frac{I / \delta_{\mathrm{CL}, \mathrm{a}}}{i_{0, \mathrm{a}}}\right) \\
& \eta_{\mathrm{act}, \mathrm{c}}=-\frac{R T}{4 \alpha_{\mathrm{c}} F} \ln \left(\frac{I / \delta_{\mathrm{CL}, \mathrm{c}}}{i_{0, \mathrm{c}}}\right)
\end{aligned}
$$

171 where $\alpha_{\mathrm{a}}$ and $\alpha_{\mathrm{c}}$ are the transfer coefficients in the anode and cathode in Table 1, 172 respectively; $I\left(\mathrm{~A} \mathrm{~m}^{-2}\right)$ is the local current density in one segment along the flow 173 direction in the anode channel; $i_{0, a}$ and $i_{0, c}\left(\mathrm{~A} \mathrm{~m}^{-3}\right)$ are the exchange current

174 densities for the anode and cathode, respectively, and are expressed as

$$
\begin{array}{r}
i_{0, \mathrm{a}}=i_{0, \mathrm{a}}^{\text {ref }}\left(1-S_{\text {ice }}-s_{\mathrm{lq}}\right)\left(\frac{c_{\mathrm{H}_{2}}}{c_{\mathrm{H}_{2}}^{\text {ref }}}\right)^{0.5} \exp \left(-1400\left(\frac{1}{T}-\frac{1}{298.15}\right)\right) \\
i_{0, \mathrm{c}}=i_{0, \mathrm{c}}^{\text {ref }}\left(1-S_{\text {ice }}-S_{\mathrm{lq}}\right) \frac{c_{\mathrm{O}_{2}}}{c_{\mathrm{O}_{2}}^{\text {ref }}} \exp \left(-7900\left(\frac{1}{T}-\frac{1}{298.15}\right)\right)
\end{array}
$$

177 where $i_{0, \mathrm{a}}^{\text {ref }}$ and $i_{0, \mathrm{c}}^{\text {ref }}\left(\mathrm{A} \mathrm{m}^{-3}\right)$ are the reference exchange current densities in the anode

178 and cathode, respectively; $s_{\mathrm{ice}}$ and $s_{\mathrm{lq}}$ are the ice and liquid water saturation in catalyst 179 layer (CL), respectively.

180 The anodic concentration loss is usually much smaller than that of the cathode, mainly 181 due to the fast hydrogen oxidation reaction. However, in the DEA or ORA mode, 
182 some local positions of the anode catalyst layer may suffer from insufficient hydrogen

183 as a result of nitrogen and liquid water accumulation, which causes remarkable 184 concentration loss. Therefore, both anodic and cathodic concentration loss are 185 considered and calculated as

$$
\eta_{\text {conc,a }}=\frac{R T}{2 \alpha_{\mathrm{a}} F} \ln \left(1-\frac{I}{I_{\mathrm{D}, \mathrm{a}}}\right)
$$

$$
\eta_{\text {conc, }}=\frac{R T}{4 \alpha_{\mathrm{c}} F} \ln \left(1-\frac{I}{I_{\mathrm{D}, \mathrm{c}}}\right)
$$

188 In those equations, $I_{\mathrm{D}, \mathrm{a}}$ and $I_{\mathrm{D}, \mathrm{c}}\left(\mathrm{A} \mathrm{m}^{-2}\right)$ are the limiting current densities and 189 calculated as [5]

$$
I_{\mathrm{D}, \mathrm{a}}=\frac{2 F c_{\mathrm{H}_{2}, \mathrm{CH}}}{\frac{\delta_{\mathrm{CL}} / 2}{D_{\mathrm{H}_{2}, \mathrm{CL}}^{\text {eff }}}+\frac{\delta_{\mathrm{MPL}}}{D_{\mathrm{H}_{2}, \mathrm{MPL}}^{\text {eff }}}+\frac{\delta_{\mathrm{GDL}}}{D_{\mathrm{H}_{2}, \mathrm{GDL}}^{\text {eff }}}}
$$

$$
I_{\mathrm{D}, \mathrm{c}}=\frac{4 F c_{\mathrm{O}_{2}, \mathrm{CH}}}{\frac{\delta_{\mathrm{CL}} / 2}{D_{\mathrm{O}_{2}, \mathrm{CL}}^{\text {eff }}}+\frac{\delta_{\mathrm{MPL}}}{D_{\mathrm{O}_{2}, \mathrm{MPL}}^{\text {eff }}}+\frac{\delta_{\mathrm{GDL}}}{D_{\mathrm{O}_{2}, \mathrm{GDL}}^{\text {eff }}}}
$$

192

194 The ohmic loss results from the ionic and electronic resistances in the fuel cell 195 components as follows,

$$
\eta_{\text {ohmic }}=-\left(\sum A S R\right) I=-\left(\frac{d}{\sigma_{\mathrm{BP}}}+\frac{\delta_{\mathrm{GDL}}}{\sigma_{\mathrm{s}, \mathrm{GDL}}^{\mathrm{eff}}}+\frac{\delta_{\mathrm{MPL}}}{\sigma_{\mathrm{s}, \mathrm{MPL}}^{\text {eff }}}+\frac{\delta_{\mathrm{CL}} / 2}{\sigma_{\mathrm{s}, \mathrm{CL}}^{\text {eff }}}+\frac{\delta_{\mathrm{CL}} / 2}{\sigma_{\mathrm{m}, \mathrm{CL}}^{\text {eff }}}+\frac{\delta_{\mathrm{MEM}}}{\sigma_{\mathrm{MEM}}}\right) I
$$

197 The current density distribution can be affected by the local reactant concentrations, 198 ice volume fraction, liquid water saturation and temperature. Electric boundary 
conditions are necessary to solve the output voltage and local current densities, and

200 the electric potentials of all segments in the flow direction are assumed to be identical

201 [29]. To solve the nonlinear equation system, Newton's method is applied with the 202 convergence error set as $1 \times 10^{-8}$ to ensure accuracy.

203

$$
\left\{\begin{array}{l}
V_{\text {out }}=V_{\text {nernst }}^{(\mathrm{i})}+\eta_{\text {act,a }}^{(i)}+\eta_{\text {act,c }}^{(i)}+\eta_{\text {act,a }}^{(i)}+\eta_{\text {conc,a }}^{(\mathrm{i})}+\eta_{\text {conc,c }}^{(\mathrm{i})}-I^{(i)} A S R^{(i)}, \mathrm{i}=1,2, \ldots, \mathrm{N} \\
\sum_{i=1}^{i=N}\left(I^{(\mathrm{i})} A_{\text {cell }} / N\right)=I_{\text {ave }} A_{\text {cell }}
\end{array}\right.
$$

\subsection{Conservation Equations}

205 The conservation equations of mass, species, nonfrozen membrane water, frozen

206 membrane water, ice, liquid pressure and energy are solved in the model. In the

207 calculations, the explicit calculation method is used to enhance calculation efficiency.

\section{2.4.1 Mass conservation}

209 Gas transport in the channels exists in the form of species diffusion and convection.

210 To simplify the model, convection is only considered along the flow direction in the

211 channels, and the convection term is dispersed by the first-order upwind scheme in the

212 current study [29]. For assumption (3) and the mass conservation equation, the 213 velocity can be expressed as [29]:

$$
\frac{\partial}{\partial t}\left(\varepsilon\left(1-S_{\mathrm{lq}}-S_{\text {ice }}\right) \rho_{\mathrm{g}}\right)+\nabla \cdot\left(\rho_{\mathrm{g}} \overrightarrow{u_{\mathrm{g}}}\right)=S_{\mathrm{m}}
$$

215 where $S_{\mathrm{m}}\left(\mathrm{mol} \mathrm{m}^{-3} \mathrm{~s}^{-1}\right)$ is the source term of all gas species in Table $3 ; \rho_{\mathrm{g}}\left(\mathrm{kg} \mathrm{m}^{-3}\right)$ 216 is the total gas concentration of segment $k$ in the channel, which can be obtained by 217 the ideal gas equation [15]. 
219 The gas species conservation equation can be solved:

$$
\frac{\partial\left(\varepsilon\left(1-S_{\text {lq }}-S_{\text {ice }}\right) \rho_{\mathrm{g}} c_{\mathrm{i}}\right)}{\partial t}=\frac{\partial^{2}\left(\rho_{\mathrm{g}} D_{\mathrm{i}}^{\mathrm{eff}} c_{\mathrm{i}}\right)}{\partial x^{2}}+S_{\mathrm{i}}
$$

221 where $S_{\mathrm{i}}\left(\mathrm{mol} \mathrm{m}^{-3} \mathrm{~s}^{-1}\right)$ is the source term of gas species $i$ in Table 3. Among the 222 porous layers, the convection flux is fixed as zero (mentioned in assumption 5).

223

\subsubsection{Liquid water transport}

234 The liquid water saturation conservation equation can be solved: diffusivity for nonfrozen membrane water and listed in Table 2.

where $S_{\text {nmw }}$ and $S_{\text {fmw }}\left(\mathrm{mol} \mathrm{m}^{-3} \mathrm{~s}^{-1}\right)$ are the nonfrozen membrane water source term and frozen membrane water source term, respectively, and the detailed phase change functions are presented in Table 3. $\rho_{\mathrm{MEM}}\left(\mathrm{kg} \mathrm{m}^{-3}\right)$ is the membrane density and $\omega_{\mathrm{p}}$ is the volume fraction of ionomer in the $p$ layer. $D_{\mathrm{nf}}\left(\mathrm{m}^{2} \mathrm{~s}^{-1}\right)$ is the 
236 where $S_{\mathrm{lq}}\left(\mathrm{mol} \mathrm{m}^{-3} \mathrm{~s}^{-1}\right)$ is the liquid water source term in Table $4 ; K_{\mathrm{lq}}\left(\mathrm{m}^{2} \mathrm{~s}^{-1}\right)$ is 237 the effective liquid permeability. The liquid pressure can be calculated by the 238 relationship of capillary pressure $\left(p_{\mathrm{g}}, \mathrm{P}_{\mathrm{a}}\right)$ and gas pressure $\left(p_{\mathrm{c}}, \mathrm{P}_{\mathrm{a}}\right)[7]$ as

$$
p_{\mathrm{lq}}=p_{\mathrm{g}}-p_{\mathrm{c}}
$$

240 The correlation equation of capillary pressure can be described by Leverett function $241[31]$ and calculated as

$$
p_{\mathrm{c}}= \begin{cases}\sigma_{\mathrm{lq}} \cos \theta\left(\frac{\varepsilon}{K_{0}}\right)^{0.5} \times\left[1.42 \mathrm{~s}_{\mathrm{lq}}-2.12\left(\mathrm{~s}_{\mathrm{lq}}\right)^{2}+1.26\left(\mathrm{~s}_{\mathrm{lq}}\right)^{3}\right] & \theta \geq 90^{\circ} \\ \sigma_{\mathrm{lq}} \cos \theta\left(\frac{\varepsilon}{K_{0}}\right)^{0.5} \times\left[1.42\left(1-\mathrm{s}_{\mathrm{lq}}\right)-2.12\left(1-\mathrm{s}_{\mathrm{lq}}\right)^{2}+1.26\left(1-\mathrm{s}_{\mathrm{lq}}\right)^{3}\right] & \theta<90^{\circ}\end{cases}
$$

243 where $\sigma_{\mathrm{lq}}\left(\mathrm{N} \mathrm{m}^{-1}\right)$ is the surface tension coefficient of liquid water; $\theta\left(^{\circ}\right)$ is the

244 contact angle in Table $1 ; \varepsilon$ is the porosity; and $K_{0}\left(\mathrm{~m}^{2}\right)$ is the intrinsic 245 permeability.

\section{$246 \quad 2.4 .5$ Ice transport}

247 Freezing point depression [15] is considered in the model defined by the parameters 248 of surface tension of water $\left(\sigma_{273.15}, \mathrm{~N} \mathrm{~m}^{-1}\right)$ at $273.15 \mathrm{~K}$, hydrophobicity $\left(\theta,{ }^{\circ}\right)$, 249 latent heat of fusion $\left(h_{\text {fusn }}, \mathrm{J} \mathrm{kg}^{-1}\right)$ and the pore radius of porous media $\left(r_{\mathrm{CL}, \mathrm{MPL}, \mathrm{GDL}}, \mathrm{m}\right)$ $250 \quad[31]:$

$$
T_{\mathrm{FPD}}=\frac{T_{\mathrm{N}} \sigma_{273.15} \cos \theta}{\rho_{\text {ice }} h_{\text {fusn }} r_{\mathrm{CL}, \mathrm{MPL}, \mathrm{GDL}}}
$$


252 Hence, the actual freezing temperatures in porous media of CL, MPL and GDL can be 253 expressed as:

$$
T_{\text {freeze }}=273.15-T_{\mathrm{FPD}}
$$

255 The ice saturation conservation equation can be solved:

$$
\frac{\partial\left(\varepsilon s_{\text {ice }} \rho_{\text {ice }}\right)}{\partial t}=S_{\text {ice }}
$$

257 where $S_{\text {ice }}\left(\mathrm{mol} \mathrm{m}^{-3} \mathrm{~s}^{-1}\right)$ is the ice source term in Table 4.

\subsubsection{Energy conservation}

259 The temperature can be solved by the energy conservation equation:

$$
\frac{\partial}{\partial t}\left(\left(\rho C_{\mathrm{p}}\right)^{\mathrm{eff}} T\right)=\frac{\hat{\partial}^{2}\left(k_{\mathrm{T}}^{\mathrm{eff}} T\right)}{\partial x^{2}}+S_{\mathrm{T}}
$$

261 where $S_{\mathrm{T}}(\mathrm{W})$ is the heat source term in Table $4 . k_{\mathrm{T}}^{\text {eff }}\left(\mathrm{W} \mathrm{m}^{-1} \mathrm{~K}^{-1}\right)$ is the effective 262 thermal conductivity. Considering the gas phase and liquid phase, the effective 263 volumetric heat capacity of each layer is defined as [15]:

$$
\begin{aligned}
\left(\rho C_{\mathrm{p}}\right)^{\mathrm{eff}}= & \varepsilon\left(\left(\mathrm{s} \rho C_{\mathrm{p}}\right)_{\mathrm{lq}}+\left(\mathrm{s} \rho C_{\mathrm{p}}\right)_{\text {ice }}+\left(1-\mathrm{s}_{\mathrm{ice}}-\mathrm{s}_{\mathrm{lq}}\right)\left(\rho C_{\mathrm{p}}\right)_{\mathrm{g}}\right) \\
& +(1-\varepsilon-\omega)\left(\rho C_{\mathrm{p}}\right)_{\mathrm{s}}+\omega\left(\rho C_{\mathrm{p}}\right)_{\mathrm{MEM}}
\end{aligned}
$$

265 In the model, the BP domain is considered the combination of solid phase (the 266 material of bipolar plate and ice), liquid phase (liquid water) and gas phase (mixed 267 gas including water vapor, hydrogen gas, oxygen gas and nitrogen gas). Therefore, the 268 effective volumetric heat capacity of the BP domain is calculated as [29]:

$$
\left(\rho C_{\mathrm{p}}\right)_{\mathrm{BP}}^{\text {eff }}=\frac{V_{\mathrm{g}}}{V_{\text {control }}}\left(\left(s \rho C_{\mathrm{p}}\right)_{\mathrm{lq}}+\left(s \rho C_{\mathrm{p}}\right)_{\text {ice }}+\left(1-S_{\text {ice }}-S_{\mathrm{lq}}\right)\left(\rho C_{\mathrm{p}}\right)_{\mathrm{g}}\right)+\frac{V_{\mathrm{s}}}{V_{\text {control }}}\left(\rho C_{\mathrm{p}}\right)_{\mathrm{s}}
$$


271 The nitrogen transport across the membrane is decided by the nitrogen pressure 272 difference between anodic and cathodic catalyst layers and membrane hydration. The 273 nitrogen crossover flux is calculated as [28]:

$$
J_{\mathrm{N}_{2}, \text { cro }}=K_{\mathrm{N}_{2}} \frac{p_{\mathrm{N}_{2}, \mathrm{c}}-p_{\mathrm{N}_{2}, \mathrm{a}}}{\delta_{\mathrm{m}}}
$$

275 where $p_{\mathrm{N}_{2}, \mathrm{a}}$ and $p_{\mathrm{N}_{2}, \mathrm{c}}\left(\mathrm{P}_{\mathrm{a}}\right)$ are the partial pressures on the two sides of the 276 membrane. $K_{\mathrm{N}_{2}}\left(\mathrm{~mol} \mathrm{~m} \mathrm{~m}^{-1} \mathrm{~s}^{-1} \mathrm{P}_{\mathrm{a}}^{-1}\right)$ is the nitrogen permeability of Nafion and is 277 expressed as [29]:

$$
K_{\mathrm{N}_{2}}=\left(0.0295+1.21 f_{v}-1.93 f_{v}^{2}\right) \times 10^{-14} \times \exp \left[\frac{E_{N_{2}}}{R}\left(\frac{1}{T_{\text {ref }}}-\frac{1}{T}\right)\right]
$$

279 where, $E_{\mathrm{N}_{2}}$ is the nitrogen activation energy $\left(24000 \mathrm{~J} \mathrm{~mol}^{-1}\right) ; T_{\text {ref }}$ is the reference 280 temperature $(303 \mathrm{~K})[27] ; V_{w}\left(\mathrm{~m}^{3} \mathrm{~mol}^{-1}\right)$ and $V_{\mathrm{m}}\left(\mathrm{m}^{3} \mathrm{~mol}^{-1}\right)$ are the molar volumes 281 of liquid water and dry membrane, respectively; and $f_{\mathrm{v}}(-)$ is the volume fraction of 282 water content and is calculated as

$$
f_{\mathrm{v}}=\frac{\lambda_{\mathrm{m}} V_{\mathrm{w}}}{V_{\mathrm{m}}+\lambda_{\mathrm{m}} V_{\mathrm{w}}}
$$

\subsection{Boundary conditions}

285 In the model, the method of heat transfer between the bipolar plate surface and the 286 environment is heat convection. Thus, the heat transfer can be expressed as [15]:

$$
Q=h\left(T_{\mathrm{en}}-T_{\mathrm{BP}}\right) A_{\mathrm{BP}}
$$


288 where $Q\left(\mathrm{~J} \mathrm{~s}^{-1}\right)$ denotes the heat transfer rate between the bipolar plate surface and 289 environment; $h\left(\mathrm{~W} \mathrm{~m}^{-2} \mathrm{~K}^{-1}\right)$ is the heat transfer coefficient in Table $1 ; A_{\mathrm{BP}}\left(\mathrm{m}^{2}\right)$ is 290 the surface area of the bipolar plate; and $T_{\mathrm{en}}$ and $T_{\mathrm{BP}}(\mathrm{K})$ are the temperatures of the 291 environment and bipolar plate surface, respectively.

292 For the flow configurations, co-flow and counter-flow are used in the model. For the 293 co-flow configuration, the inlets of the anode and cathode are on the same side of the 294 channels; for the counter-flow configuration, it is the reverse.

295 Hydrogen flow arrangements can be divided into three modes as FTA, DEA, and 296 ORA. For each mode, the boundary conditions for the anode channels are different. 297 For the FTA mode, the flow velocities and concentrations at the inlets of flow 298 channels are calculated as

$$
\begin{array}{ll}
u_{\mathrm{a}, \mathrm{in}}=\frac{S T_{\mathrm{a}} I_{\mathrm{ave}} A_{\mathrm{cell}}}{2 F c_{\mathrm{H}_{2}, \mathrm{in}} A_{\mathrm{ACH}}}, & u_{\mathrm{c}, \mathrm{in}}=\frac{S T_{\mathrm{c}} I_{\mathrm{ave}} A_{\text {cell }}}{4 F c_{\mathrm{O}_{2}} A_{\mathrm{CCH}}} \\
c_{\mathrm{H}_{2}, \mathrm{in}}=\frac{p_{\mathrm{g}}^{\mathrm{a}}-R H_{\mathrm{a}} p_{\mathrm{sat}}}{R T_{\mathrm{in}}^{\mathrm{a}}}, & c_{\mathrm{O}_{2}, \text { in }}=\frac{0.21\left(p_{\mathrm{g}}^{\mathrm{c}}-R H_{\mathrm{c}} p_{\mathrm{sat}}\right)}{R T_{\mathrm{in}}^{\mathrm{c}}}
\end{array}
$$

301 Here, $S T_{\mathrm{a}}$ and $S T_{\mathrm{c}}$ are the stoichiometry ratios for the anode and cathode. $I_{\text {ave }}$ $302\left(\mathrm{~A} \mathrm{~m}^{-2}\right)$ is the average current density for the cell. $A_{\mathrm{ACH}}$ and $A_{\mathrm{CCH}}\left(\mathrm{m}^{2}\right)$ are the gas

303 flow flux areas at the anode and cathode, respectively. $A_{\text {cell }}\left(\mathrm{m}^{2}\right)$ is the total active 304 surface area. The inlet gas is assumed to be fully preheated, and the inlet gas 305 temperatures are equal to the local cell temperature.

306 For the DEA mode, the flow velocities at the outlet of anode channel and the inlet of 307 the cathode channel are calculated as 


$$
u_{\mathrm{a}, \mathrm{in}}=0, \quad u_{\mathrm{c}, \mathrm{in}}=\frac{S T_{\mathrm{c}} I_{\mathrm{ave}} A_{\mathrm{cell}}}{4 F c_{\mathrm{O}_{2}} A_{\mathrm{CCH}}}
$$

$$
c_{\mathrm{H}_{2}, \text { out }}=c_{\mathrm{H}_{2}, \mathrm{ACH}}^{\mathrm{t}-\Delta \mathrm{t}}, \quad c_{\mathrm{O}_{2}, \mathrm{in}}=\frac{0.21\left(p_{\mathrm{g}}^{\mathrm{c}}-R H_{\mathrm{c}} p_{\mathrm{sat}}\right)}{R T_{\mathrm{in}}^{c}}
$$

310 where $c_{\mathrm{H}_{2}, \mathrm{ACH}}^{\mathrm{t}-\mathrm{t}}\left(\mathrm{mol} \mathrm{m}^{-3}\right)$ is the hydrogen concentration at the outlet of the anode

311 channel in the previous time step.

312 For the ORA mode, the flow from the outlet is assumed as being reserved and

313 recirculated at the new time step [29]. The inlet flow velocities $\left(\mathrm{m} \mathrm{s}^{-1}\right)$ are calculated 314 as

$$
u_{\mathrm{a}, \text { in }}=\frac{S T_{\mathrm{a}} \frac{I_{\text {ave }}}{2 F} A_{\text {cell }}+\phi_{\mathrm{N}_{2}, \text { out }}^{\mathrm{t}-\Delta \mathrm{t}}+\phi_{\mathrm{vp}, \mathrm{out}}^{\mathrm{t}-\Delta \mathrm{t}}}{c_{\text {total }} A_{\mathrm{ACH}}}, \quad u_{\mathrm{c}, \text { in }}=\frac{S T_{\mathrm{c}} I_{\text {ave }} A_{\mathrm{cell}}}{4 F_{\mathrm{C}_{2}} A_{\mathrm{CCH}}}
$$

317 where $\phi_{\mathrm{N}_{2}, \text { out }}^{\mathrm{t}-\Delta \mathrm{t}}$ and $\phi_{\mathrm{vp}, \text { out }}^{\mathrm{t}-\Delta \mathrm{t}}\left(\mathrm{mol} \mathrm{s}^{-1}\right)$ are the nitrogen flux and vapor flux, respectively, 318 at the outlet of the anode channel $(\mathrm{ACH})$ at $t-\Delta t ; c_{\mathrm{N}_{2}, \text { out }}^{\mathrm{t}-\mathrm{t}}$ and $c_{\mathrm{vp}, \mathrm{out}}^{\mathrm{t}-\mathrm{t}}\left(\mathrm{mol} \mathrm{m}^{-3}\right)$ are the 319 nitrogen and vapor concentrations, respectively, at the outlet of $\mathrm{ACH}$ at $t-\Delta t$ and $320 c_{\text {total }}\left(\mathrm{mol} \mathrm{m}^{-3}\right)$ is the sum of all gas component concentrations at the ACH inlet based 321 on the ideal gas equation.

$$
\phi_{\mathrm{N}_{2}, \text { out }}^{\mathrm{t} \Delta \mathrm{t}}=c_{\mathrm{N}_{2}, \text { out }}^{\mathrm{t}-\Delta \mathrm{t}} A_{\mathrm{ACH}} u_{\mathrm{a}, \text { out }}^{\mathrm{t}-\Delta \mathrm{t}}
$$

$$
\phi_{\mathrm{vp}, \text { out }}^{\mathrm{t}-\Delta \mathrm{t}}=c_{\mathrm{vp}, \text { out }}^{\mathrm{t}-\Delta \mathrm{t}} A_{\mathrm{ACH}} u_{\mathrm{a}, \text { out }}^{\mathrm{t}-\Delta \mathrm{t}}
$$


325 The numerical model is solved by a self-written program and run by MATLAB. In 326 this model, the size of a single time step is fixed as $1 \times 10^{-6} \mathrm{~s}$ to avoid divergence and 327 guarantee calculation accuracy due to the explicit scheme applied to disperse control 328 equations. The grid-independency has been tested, and the difference in cell voltage 329 between 5 segments and 10 segments is less than $1 \%$. Considering the computational 330 efficiency, 5 segments is suitable for calculation [29]. To comprehend how the 331 mathematical model works, Fig. 2 shows the flow chart of the calculation process. In 332 Fig. 2, the physical variables include the velocity, gas species, membrane water, 333 liquid water, ice and temperature.

\section{3. Results and discussion}

335 In the paper, the features of three hydrogen flow arrangements, flow-through anode 336 (FTA), dead-ended anode (DEA) and off-gas recirculation anode (ORA), are analyzed 337 in detail to investigate their effects on startup processes from subzero to normal 338 operating temperatures. The comparisons between two flow configurations (co-flow 339 or counter-flow) and two start-up strategies (high start voltage or low start voltage) 340 are also analyzed in detail.

\subsection{Model validation}

342 To verify the model accuracy, simulation results are compared with data from 343 self-designed experiments. Fig. 3 shows that the model has been validated against 344 experimental data for cold-start processes and cell polarization curves. In Fig. 3 (a), 345 the simulation and results reasonably match with the experimental evolutions of cell 346 voltage and ohmic loss voltage in the failed and successful cold-start processes from $347-6^{\circ} \mathrm{C}$ and $-9{ }^{\circ} \mathrm{C}$; the initial membrane water content was $\lambda=3.24,4.59,2.33$. The

348 operating current density was constant at $1000 \mathrm{~A} \mathrm{~m}^{-2}$. The FTA mode and 
counter-flow configuration are applied in experiments by default. In Fig. 3 (a), the

350 most error rate of cell voltage between simulation and experiment is approximately

$3514 \%$. This error rate is within the allowed range. In Fig. 3 (b), the simulation results are

352 consistent with the experimental data with different inlet relative humidities. The

353 relative modeling parameters (Table 1) such as geometric parameters and

354 electrochemical parameters are kept constant in those operations. The predictions of

355 the model are consistent with the experimental data, and the reasonable modeling

356 accuracy is acquired at different operating temperatures. The validations of the DEA

357 and ORA modes have been done in the previous work [29, 34]. Fig. 3 (c) shows the

358 comparison of dynamic performances of the PEM fuel cells with DEA between model

359 prediction and experiment [32]. The boundary conditions of the model are the same as

360 those in the experiments [32]. Fig. 3 (d) shows the comparison of the dynamic

361 performances of the PEM fuel cells with the ORA between the experiment [33] and

362 model prediction. The grid-independency has also been tested in the dynamic process

363 in Fig. 3 (d). There is no big influence for the dynamic performance when the grid

364 number is growing from 5 to 10.

\subsection{Effects of the flow configurations on the hydrogen flow arrangements}

366 In this section, three successful startup processes from subzero temperature of the

367 PEM fuel cell with different hydrogen flow arrangements are discussed in detail. To

368 investigate the effects of different flow configurations on the cold-start capacity,

369 galvanostatic operation $\left(1000 \mathrm{~A} \mathrm{~m}^{-2}\right)$ is adopted to guarantee the same generating rate

370 of water in the cells.

371 Figure 4 displays the evolutions of the output voltage with three hydrogen flow 372 arrangements starting from $267.15 \mathrm{~K}$ with constant-current operation at $1000 \mathrm{~A} \mathrm{~m}^{-2}$ 373 and no humidity at the inlets. During the entire processes, the output voltages change 374 in a wide range due to the membrane hydration and ice accumulation [5]. In Figs. 4 (a) 375 and 4 (b), the hydrogen flow arrangements have very small effects on the 
376 performances in the first $200 \mathrm{~s}$. From $200 \mathrm{~s}$ to $900 \mathrm{~s}$, the output voltages generally

377 decrease, and in DEA mode, the largest voltage drop appears with both flow 378 configurations. At $900 \mathrm{~s}$, cell voltages in the DEA mode and FTA mode can differ by $37940 \mathrm{mV}$ at most. Simultaneously, the cell voltages are approximately $15 \mathrm{mV}$ higher in 380 co-flow case than in counter-flow cases. Among the three hydrogen flow 381 arrangements, the output performance is always the best in the FTA mode and the 382 worst in the DEA mode.

383 Figure 5 presents the evolutions of ice saturation in the cathode catalyst layer (CCL) 384 in the first $150 \mathrm{~s}$. The hydrogen flow arrangements slightly affect the ice saturation 385 distributions in the first $150 \mathrm{~s}$, especially in the counter-flow modes. Most ice 386 saturation during the cold-start process in the co-flow modes is over 0.50 but less than 3870.25 in the counter-flow modes. Combined with Fig. 4, the difference in ice formation 388 accumulation in two flow configurations can be explained by the ability of 389 self-humidification ability. Stronger self-humidification can promote a better cell 390 performance at temperatures above freezing and lead to more ice formation and 391 accumulation in CCL at subzero temperatures [17]. Affected by current density 392 distributions, more water is generated close to the upstream cathode channel in the 393 co-flow mode than in the counter-flow mode. More water in the co-flow mode can be 394 absorbed in the downstream membrane in the form of vapor.

395 Figure 6 displays the evolutions of the current density distribution (Fig. 6 (a)), 396 temperature distribution (Fig. 6 (b)) and nitrogen concentration distribution (Fig. 6 (c)) 397 with three hydrogen flow arrangements in the counter-flow mode. The current density 398 distributions in the FTA and ORA modes are similar but differ from that in the DEA 399 mode, especially after $300 \mathrm{~s}$ (Fig. 6 (a)). At $900 \mathrm{~s}$, the local current density near the 400 anode exit in the DEA mode is the minimum and lower than $150 \mathrm{~A} \mathrm{~m}^{-2}$, but in the 401 FTA mode and ORA mode, it is the maximum along the channel. The variation 402 tendency of the temperature distribution is similar to that of the current density 
403 distribution (Fig. 6 (b)); since the local current density can directly affect the ohmic

404 heat power and other heat sources. The current density in the DEA mode decreases

405 below $450 \mathrm{~A} \mathrm{~m}^{-2}$ near the exit of the anode channel at $750 \mathrm{~s}$, and the heating power

406 cannot satisfy the heat loss from the cell into the cold environment. Later temperature

407 near the inlet of cathode is approximately the freezing point in the DEA mode at $900 \mathrm{~s}$

408 in Fig. 6(b), which may lead a failing startup process. The nitrogen distributions are

409 quite different in three cases due to hydrogen flow arrangements (Fig. 6 (c)). The

410 nitrogen concentration relatively uniformly distributes in the ORA mode, but most of

411 the nitrogen concentrates in the downstream area of anode catalyst layer in the DEA

412 mode. Comparing with the results in Fig. 6 (a) and (c), the local current density

413 decreases when the nitrogen concentration increases from 0 to $43.0 \mathrm{~mol} \mathrm{~m}^{-3}$ in the

414 DEA mode. Although the problems of nitrogen crossover and gathering also exist in

415 the ORA mode, the anode recirculation loops can force nitrogen convection and the

416 maximum of nitrogen concentration in the anode catalyst layer is approximately 27

$417 \mathrm{~mol} \mathrm{~m}^{-3}$ at $900 \mathrm{~s}$ while hydrogen remains relatively adequate for

418 electrochemical reaction. More nitrogen concentration and more nonuniform nitrogen

419 distribution are the main reasons [22, 23, 32] that cause the worst performance to the

420 DEA mode as shown in Fig. 4.

421 Figure 7 shows the evolutions of hydrogen use efficiencies of PEM fuel cells with

422 three hydrogen flow arrangements during the startup processes. The hydrogen use

423 efficiency $(\eta)$ is calculated as [29]:

$$
\eta=\frac{\sum\left(I_{\text {ave }} V_{\text {out }}\right) A_{\text {cell }}}{\sum\left(u_{\mathrm{a}, \mathrm{in}} c_{\mathrm{H}_{2}, \text { in }}\right) M_{\mathrm{H}_{2}} L H V_{\mathrm{H}_{2}} A_{\mathrm{ACH}}}
$$

425 here $L H V_{\mathrm{H}_{2}}\left(\mathrm{~J} \mathrm{~kg}^{-1}\right)$ is the lower heating value of hydrogen, and $M_{\mathrm{H}_{2}}\left(\mathrm{~kg} \mathrm{~mol}^{-1}\right)$ is 426 the molar mass of hydrogen gas. The efficiencies in the DEA and ORA modes are 427 often nearly identical and much larger than that in the FTA mode. However, after 500 
$428 \mathrm{~s}$, a clear decline in efficiency appears in the DEA mode, which implies that the

429 nitrogen crossover causes a larger activation loss in ACL than in ORA mode [26, 29].

$430 \quad 3.3$ Effects of the startup voltages on the hydrogen flow arrangements

431 Generally, $0.65 \mathrm{~V}$ is considered as a common operating voltage when the fuel cell 432 works at a state of high output power and high hydrogen use efficiency in normal 433 temperature operation $[35,36]$. Therefore, a successful cold start with 434 constant-voltage operation at $0.65 \mathrm{~V}$ from subzero to normal operating temperatures 435 has strong practical significance for automobile applications. However, under the 436 requirement of rapid start from subzero temperature, startup with a low voltage 437 operation is considered an effective method for a rapid cold start [15]. In this section, 438 the effects of startup voltages on PEM fuel cells with three hydrogen flow 439 arrangements are analyzed in detail and relative conditions are listed in Table 1 . In the 440 following content, all cases with the counter-flow configuration are arranged as 441 default. The flow rates of gases are calculated by the output current at the last time 442 step and stoichiometric ratio.

443 Figure 8 shows the evolutions of the average output current density with three 444 hydrogen flow arrangements with different voltage operations at $0.65 \mathrm{~V}$ and $0.3 \mathrm{~V}$. 445 The average output current densities of three hydrogen flow arrangements in the $4460.65-\mathrm{V}$ cases are from $650-1050 \mathrm{~A} \mathrm{~m}^{-2}$. At $0.3 \mathrm{~V}$, they are $4000-12000 \mathrm{~A} \mathrm{~m}^{-2}$. In 447 comparison with the processes at two operation voltages, the average output current 448 densities of three modes obviously vary at $0.65 \mathrm{~V}$, especially at $250 \mathrm{~s}$, with similar 449 trends to the other low-current operations in Fig. 4 (b). However, at $0.3 \mathrm{~V}$, the cell 450 performance of the DEA mode starts to decrease when the performances of the other 451 modes continuously increase at $75 \mathrm{~s}$, which is caused by the nitrogen crossover and 452 accumulation in the anode $[33,34]$. 
453 Figure 9 displays the evolutions of the ice accumulation distributions in CCL with 454 constant-voltage operations at $0.65 \mathrm{~V}$ and $0.3 \mathrm{~V}$. Obviously, during the startup 455 processes, the ice saturation can be over 0.25 in the $0.65-\mathrm{V}$ cases but less than 0.1 in 456 the $0.3-\mathrm{V}$ cases. In $0.3-\mathrm{V}$ cases, there is ice for fewer than $10 \mathrm{~s}$ due to the large 457 voltage loss and heat source. Although the larger current in the $0.3-\mathrm{V}$ cases can result 458 in a faster rate of water formation, starting at $0.3 \mathrm{~V}$ is better in terms of cold-start 459 capacity.

460 Figure 10 presents the evolutions of the current density distributions (Fig. 10 (a)), 461 temperature distributions (Fig. 10 (b)) and nitrogen concentration distributions (Fig. $46210(\mathrm{c}))$ with a constant-voltage operation at $0.65 \mathrm{~V}$. The FTA and ORA modes have 463 similar trends of current density distribution in the entire processes. At the same place 464 of the channel, the local current density in the FTA mode is a little higher than that in 465 the ORA mode, which corresponds to the curves of FTA and ORA modes in Fig. 8 (a). 466 In the DEA mode, the local current density at the fifth segment decreases over time 467 due to the nitrogen concentration accumulation. The effect of nitrogen accumulation 468 on the ORA mode is not as obvious as that in the DEA mode. Compared with the 469 FTA mode, the nitrogen crossover and gathering slightly affect the output 470 performance in the ORA mode. The same reason is presented in section 4.2. In Fig. $47110(\mathrm{c})$, the highest temperatures are approximately $280 \mathrm{~K}$ in the processes and locate 472 near the inlet of the cathode channel in the FTA and ORA modes. In the DEA mode, 473 the highest temperature is at the middle of CCL due to the distribution of local current 474 density.

475 Figure 11 displays the evolutions of the current density distribution (Fig. 11 (a)), 476 temperature (Fig. 11 (b)) and nitrogen concentration distribution (Fig. 11 (c)) with a 477 constant-voltage operation at $0.3 \mathrm{~V}$. The local current densities in the $0.3-\mathrm{V}$ cases 478 exceed $10000 \mathrm{~A} \mathrm{~m}^{-2}$ at $80 \mathrm{~s}$. In the DEA mode, the local current density near the exit 479 of the anode gradually decreases after $60 \mathrm{~s}$ because the nitrogen concentration 
480 increases to a high level in Fig. 11 (a). According to the experimental results [37], a 481 larger operating current can accelerate the rate of nitrogen crossover and 482 accumulation in the anode, which can be verified in the $0.3-\mathrm{V}$ cases. As we expected, 483 the startup with a low voltage operation can accelerate the process of heating the cell 484 and lead to a rapidly successful cold start. At $80 \mathrm{~s}$, the highest temperatures can 485 exceed $340 \mathrm{~K}$ in three modes. For three hydrogen flow arrangements, the differences 486 among temperature distributions can be ignored in a short start time.

487 Generally, the $0.3-\mathrm{V}$ cases have an advantage over the $0.65-\mathrm{V}$ cases with the shorter 488 heating-up time and better uniformity. In the simulation results, the startup with $0.3-\mathrm{V}$ 489 operation can motivate a huge current density and shorten the cold-start process, and 490 the effort of nitrogen crossover can be safely ignored in the DEA and ORA cases compared with the FTA cases due to the startup of $80 \mathrm{~s}$.

\section{Conclusion}

In the study, the dynamic characteristics in the start-up process with different

494 hydrogen flow arrangements are systematically analyzed for the PEM fuel cell. Based 495 on the numerical investigations, the major conclusions are as follows:

496 1. During startup processes, co-flow cases can cause much more ice formation 497 accumulation in CCL than the counter-flow cases. The hydrogen flow 498 arrangements can hardly affect the ice formation distributions.

499 2. Starting at a low operating voltage can remarkably shorten the start time and 500 effectively avoid the hydrogen starvation in PEM fuel cells with a dead-ended 501 anode or an off-gas recirculation anode during the startup processes.

502 3. The PEM fuel cell with an off-gas recirculation anode or a flow-through anode 503 has similar dynamic characters in startup processes in terms of ice formation, local $504 \quad$ current density and temperature distributions. 
505

506

507

508

509

510

511

512

513

514

515

516

517

518

519

520

521

522

523

524

525

526

4. A PEM fuel cell with a low voltage operation, an off-gas recirculation anode and a counter-flow configuration is the ideal combination during the cold-start process in the items of the best hydrogen utilization efficiency, good anodic nitrogen tolerance, high output performance and good cold-start capacity.

In general, the development of the quasi-2D cold-start model and the relative work presented in the study are expected to assist the selections of hydrogen supply arrangements and startup strategies for the cold-start process of the PEM fuel cell. In the future, the more complicated strategy should be considered in the cold-start process including a variable load and heating the coolant. The cold-start model can also be combined with AI technology so that the faster prediction and optimization can be achieved in a few seconds $[38,39]$. More practical applications such as online control for PEM fuel cell can be based on the model [39].

\section{Acknowledgements}

This research is supported by the National Key Research and Development Program of China (Grant No. 2018YFB0105505), National Natural Science Foundation of China for Excellent Young Scholars (Grant No. 51622606), Natural Science Foundation for Outstanding Young Scholars of Tianjin (Grant No. 18JCJQJC46700) and China-UK International Cooperation and Exchange Project (Newton Advanced Fellowship), which is jointly supported by the National Natural Science Foundation of China (Grant No. 51861130359) and the UK Royal Society (Grant No.

NAF $\backslash R 1 \backslash 180146)$.

\section{References}


528 [1] Jiao K, Ni M. Challenges and opportunities in modelling of proton exchange 529 membrane fuel cells (PEMFC)[J]. International Journal of Energy Research, 2017, $530 \quad 41(13)$.

531 [2] Liu F, Zhao F, Liu Z, et al. The impact of fuel cell vehicle deployment on road 532 transport greenhouse gas emissions: The China case[J]. International Journal of 533 Hydrogen Energy, 2018, 43(50): 22604-22621.

534 [3] Amamou A, Kandidayeni M , Boulon L, et al. Real time adaptive efficient cold 535 start strategy for proton exchange membrane fuel cells[J]. Applied Energy, 2018, $536 \quad 216: 21-30$.

537 [4] Chen H, Song Z, Zhao X, et al. A review of durability test protocols of the 538 proton exchange membrane fuel cells for vehicle[J]. Applied Energy, 2018, $539 \quad 224: 289-299$.

540 [5] Luo Y, Jiao K. Cold start of proton exchange membrane fuel cell[J]. Progress in $541 \quad$ Energy and Combustion Science, 2017, 64: 29-61.

542 [6] Tajiri K, Tabuchi Y, Kagami F, et al. Effects of operating and design parameters 543 on PEFC cold start[J]. Journal of Power Sources, 2007, 165(1):279-286.

544 [7] Jiao K, Li X. Effects of various operating and initial conditions on cold start 545 performance of polymer electrolyte membrane fuel cells[J]. International Journal 546 of Hydrogen Energy, 2009, 34(19):8171-8184.

547 [8] Xie X, Zhang G, Zhou J, et al. Experimental and theoretical analysis of 548 ionomer/carbon ratio effect on PEM fuel cell cold start operation[J]. International $549 \quad$ Journal of Hydrogen Energy, 2017, 42(17): 12521-12530.

550 [9] Yang Z, Du Q, Huo S, et al. Effect of membrane electrode assembly design on 551 the cold start process of proton exchange membrane fuel cells[J]. International 552 Journal of Hydrogen Energy, 2017,42(40):25372-25387.

553 [10]Morin A, Peng Z, Jestin J, et al. Water management in proton exchange 554 membrane fuel cell at sub-zero temperatures: An in operando SANS-EIS coupled 555 study[J]. Solid State Ionics, 2013, 252:56-61. 
556 [11]Lin R, Weng Y, Lin X, et al. Rapid cold start of proton exchange membrane fuel

557 cells by the printed circuit board technology[J]. International Journal of Hydrogen

$558 \quad$ Energy, 2014, 39(32): 18369-18378.

559 [12]Lin R, Lin X, Weng Y, et al. Evolution of thermal drifting during and after cold

560 start of proton exchange membrane fuel cell by segmented cell technology[J].

561 International Journal of Hydrogen Energy, 2015, 40(23): 7370-7381.

562 [13]Lin R, Ren Y S, Lin X W, et al. Investigation of the internal behavior in 563 segmented PEMFCs of different flow fields during cold start process[J]. Energy, $564 \quad 2017,123: 367-377$.

$565[14]$ Zhu Y, Lin R, Jiang Z, et al. Investigation on cold start of polymer electrolyte 566 membrane fuel cells with different cathode serpentine flow fields[J]. International 567 Journal of Hydrogen Energy, 2019, 44(14): 7505-7517.

568 [15]Jiao K, Li X. Three-dimensional multiphase modeling of cold start processes in 569 polymer electrolyte membrane fuel cells[J]. Electrochimica Acta, 2009, 54(27): $570 \quad 6876-6891$.

571 [16]Jiao K, Alaefour I E, Karimi G, et al. Cold start characteristics of proton 572 exchange membrane fuel cells[J]. international journal of hydrogen energy, 2011, 573 36(18): 11832-11845.

574 [17]Gwak G, Ko J, Ju H. Numerical investigation of cold-start behavior of 575 polymer-electrolyte fuel-cells from subzero to normal operating 576 temperatures-effects of cell boundary and operating conditions[J]. International 577 Journal of Hydrogen Energy, 2014, 39(36): 21927-21937.

578 [18]Zhigang Z, Chong Y, Zhangrong H, et al. Experimental study on different 579 preheating methods for the cold-start of PEMFC stacks[J]. Energy, 2018, $580 \quad 162: 1029-1040$.

581 [19]Liu Y, Lehnert W, Jan En H , et al. A review of high-temperature polymer 582 electrolyte membrane fuel-cell (HT-PEMFC)-based auxiliary power units for 583 diesel-powered road vehicles[J]. Journal of Power Sources, 2016, 311:91-102. 
584 [20]Guangjin W, Yi Y, Hai L, et al. Progress on design and development of polymer 585 electrolyte membrane fuel cell systems for vehicle applications: A review[J]. Fuel $586 \quad$ Processing Technology, 2018, 179:203-228.

587 [21]Chen J, Siegel J B, Stefanopoulou A G, et al. Optimization of purge cycle for 588 dead-ended anode fuel cell operation[J]. International Journal of Hydrogen $589 \quad$ Energy, 2013, 38(12):5092-5105.

590 [22] Yesilyurt S, Siegel J B, Stefanopoulou A G. Modeling and experiments of voltage 591 transients of polymer electrolyte membrane fuel cells with the dead-ended $592 \quad$ anode[J]. Journal of Fuel Cell Science and Technology, 2012, 9(2): 021012.

593 [23]Yang C W, Chen Y S. A mathematical model to study the performance of a 594 proton exchange membrane fuel cell in a dead-ended anode mode[J]. Applied $595 \quad$ Energy, 2014, 130: 113-121.

596 [24]Yang Y, Zhang X, Guo L, et al. Overall and local effects of operating conditions 597 in PEM fuel cells with dead-ended anode[J]. International Journal of Hydrogen $598 \quad$ Energy, 2017, 42(7): 4690-4698.

599 [25]Bao C, Ouyang M, Yi B. Modeling and control of air stream and hydrogen flow 600 with recirculation in a PEM fuel cell system-I. Control-oriented modeling[J]. 601 International journal of hydrogen energy, 2006, 31(13): 1879-1896.

602 [26]Wang B, Deng H, Jiao K. Purge strategy optimization of proton exchange 603 membrane fuel cell with anode recirculation[J]. Applied Energy, 2018, 225: 1-13. 604 [27]Ahluwalia R K, Wang X. Buildup of nitrogen in direct hydrogen 605 polymer-electrolyte fuel cell stacks[J]. Journal of Power Sources, 2007, 171(1): $606 \quad 63-71$.

607 [28]Promislow K, St-Pierre J, Wetton B. A simple, analytic model of polymer 608 electrolyte membrane fuel cell anode recirculation at operating power including 609 nitrogen crossover[J]. Journal of Power Sources, 2011, 196(23): 10050-10056. 
610 [29]Wang B, Wu K, Yang Z, et al. A quasi-2D transient model of proton exchange

611 membrane fuel cell with anode recirculation[J]. Energy conversion and

612 management, 2018, 171: 1463-1475.

613 [30]Huo S, Jiao K, Park J W. On the water transport behavior and phase transition

614 mechanisms in cold start operation of PEM fuel cell[J]. Applied Energy, 2019, $615 \quad 233: 776-788$.

616 [31]Jiao K, Li X. Water transport in polymer electrolyte membrane fuel cells[J].

617 Progress in Energy \& Combustion Science, 2011, 37(3):221-291.

618 [32]Chen Y S, Yang C W, Lee J Y. Implementation and evaluation for anode purging

619 of a fuel cell based on nitrogen concentration[J]. Applied Energy, 2014, $620 \quad 113(1): 1519-1524$.

621 [33]Lee, Heng-Yi, Su, et al. A gas management strategy for anode recirculation in a 622 proton exchange membrane fuel cell[J]. International Journal of Hydrogen $623 \quad$ Energy, 2018, 43(7):3803-3808.

624 [34]Wang B, Wu K, Xi F, et al. Numerical analysis of operating conditions effects on 625 PEMFC with anode recirculation[J]. Energy, 2019, 173(4):844-856.

626 [35]Livshits V, Ulus A, Peled E. High-power H2/Br2 fuel cell[J]. Electrochemistry 627 communications, 2006, 8(8): 1358-1362.

628 [36] Mathias M F, Makharia R, Gasteiger H A, et al. Two fuel cell cars in every 629 garage[J]. Electrochem. Soc. Interface, 2005, 14(3): 24-35.

630 [37]Rabbani R A, Rokni M . Effect of nitrogen crossover on purging strategy in PEM 631 fuel cell systems[J]. Applied Energy, 2013, 111(11):1061-1070.

632 [38]A. Bejan. AI and freedom for evolution in energy science[J]. Energy and AI, 633 accepted.

634 [39]Wang B, Zhang G, Wang H, et al. Multi-Physics-Resolved Digital Twin of 635 Proton Exchange Membrane Fuel Cells with A Data-Driven Surrogate Model[J]. $636 \quad$ Energy and AI, accepted. 